\title{
Ozone Therapy and Aquatic Rehabilitation Exercises to Overcome the Lumbar Pain Caused by Facet Joint Syndrome - Case Report
}

This article was published in the following Dove Press journal: International Medical Case Reports Journal

\author{
Rosa Grazia Bellomo',* \\ Teresa Paolucci ${ }^{2 * *}$ \\ Niki Giannandrea $\mathbb{D}^{2}$ \\ Letizia Pezzi $\mathbb{D D}^{2}$ \\ Raoul Saggini ${ }^{2}$ \\ 'University of Study of Urbino Carlo Bo, \\ Department of Biomolecular Sciences, \\ Urbino, Italy; ${ }^{2}$ University G.d'Annunzio \\ Chieti, Physical Medicine and \\ Rehabilitation, Department of Medical \\ and Oral Sciences and Biotechnologies \\ (DSMOB), Chieti-Pescara, Italy \\ *These authors contributed equally to \\ this work
}

Correspondence: Teresa Paolucci University G.d'Annunzio Chieti, Department of Medical and Oral Sciences and Biotechnologies, Viale Abruzzo 322, Chieti-Pescara 66100 CH, Italy Email teresapaolucci@hotmail.com
Purpose: Facet joint syndrome (FJS) is an arthritis-like condition of the spine that can be a significant source of low back pain (LBP). Ozone therapy (OT) could be an additional treatment method. We evaluated the therapeutic results of percutaneous injection of ozone to ablate acute LBP caused by FJS.

Methods: A 73-year-old Caucasian woman was treated by OT: one ozone injection $(20 \mu \mathrm{g} / \mathrm{mL})$ per week for 3 weeks under ultrasound guidance. After a break of 1 week, she performed exercises for aquatic rehabilitation (twice a week for 4 weeks).

Results: The outcome measure was pain relief for $\geq 6$ months according to the Numeric Rating Scale (NRS), Oswestry Disability Index (ODI), and Brief Pain Inventory (BPI) test. From baseline to 1 month after OT, a reduction in pain was documented and the result was maintained at 6-month follow-up.

Conclusion: OT followed by aquatic exercises could be efficacious against the LBP caused by FJS.

Keywords: ozone, low back pain, Oswestry Disability Index, spine, injection

\section{Introduction}

Low back pain (LBP) is a common health problem in the workplace. In fact, LBP is the most common musculoskeletal complaint in the general population, and almost everyone will experience LBP at least once in his/her life. Moreover, it is the most common cause of disability in individuals younger than 45 years. ${ }^{1}$

LBP management is dependent upon its etiology, pain duration, presence of radiculopathy as well as the findings of radiology or physical examination. ${ }^{2}$ The differential diagnosis has a fundamental role in achieving therapeutic success. ${ }^{3}$ Moreover, the findings of diagnostic imaging, such as magnetic resonance imaging (MRI), often do not correlate with the subjective symptoms of LBP. ${ }^{4,5}$

Facet joint syndrome (FJS) is a common cause of LBP. FJS has been shown to be the culprit in 15-45\% of patients with LBP: typically, there is more discomfort while leaning backward than while leaning forward. ${ }^{6-8}$ FJS is a painful irritation of the posterior part of the lumbar spine and swelling from the surrounding structures, and can cause pain due to irritation of nerve roots. Selective anesthesia of the medial branch of the dorsal primary ramus of the spinal nerve innervating the facet joint can be undertaken to diagnose FJS. ${ }^{9}$ Often, the diagnosis is confirmed by local anesthetic blocks of facet joints or medial branches to elicit rapid relief from 
pain. ${ }^{10,11}$ This procedure can be undertaken under fluoroscopic or computed-tomography guidance, but the latter is associated with radiation exposure, scarce availability, and high costs. Conversely, ultrasound does not involve radiation, is not expensive, and is readily available (but operator-dependent). ${ }^{7}$

Low threshold, rapidly adapting mechanosensitive receptors provide facet joints with the ability to transmit proprioceptive information in addition to nociceptive information. Facet joints have rich innervation represented by nociceptive fibers that have central roles in pain transmission if they are excited. Chemical stimulation or mechanical stimulation of these receptors has been shown to elicit pain in the back and/or legs.,12,13 A common medical approach for lumbar pain from FJS is anti-inflammatory drugs, myorelaxants, "lumbar corsets", and rehabilitation but, in many cases, the lumbar pain remains. $1,2,14,15$

Recently, ozone therapy (OT) based on intraarticular injection of ozone has shown good efficacy in lumbar-disk herniation if more conservative management fails or antiinflammatory agents are contraindicated. ${ }^{16,17}$

Alexander et al showed that $80 \%$ of patients had good outcomes after ozone injection in herniated cervical disks. ${ }^{18,19}$ The efficacy of OT is poor in patients who have large herniation of lumbar disks but good in those with small/minimal herniation of disks.

\section{Case Report Ethical Approval}

This case report fulfilled the obligations set by the Helsinki Declaration 1975 and its later amendments. The patient gave written informed consent after receiving detailed information on the study's aims and procedures, the risks involved, and was enlightened about the variable therapeutic outcomes. The patient also provided written informed consent for her data to be used for publication. No institutional approval was required to publish the case details.

\section{Presentation}

A 73-year-old Caucasian woman was treated at the Rehabilitation Unit of D'Annunzio University of Chieti (Chieti, Italy). She had a diagnosis of acute LBP for left FJS with respect to L1-L5 and S1. Before OT, for 4 months she took tapentadol (prolonged release; $50 \mathrm{mg} /$ day) and pregabalin (75 mg/day) for referred lumbar pain.
The patient did not have allergies. She did not have sacroiliitis, bone lesions, bleeding disorders, local infection, thrombocytopenia, recent myocardial infarction/ stroke, or a pacemaker. She was not taking anticoagulants or antiplatelet therapy and had not undergone spinal surgery previously.

Clinical data were collected at baseline T0 (before treatment), T1 (after 2 weeks of treatment), T2 (after 1 month of treatment), T3 (after 2 months of treatment), and T4 (after 6 months of treatment). She presented for physical examination due to para-spinal tenderness and pain that increased upon hyperextension, rotation, and lateral bending of the lumbar spine; neurologic deficits were not observed.

\section{Pain Scales}

Three scales were used for LBP evaluation. The Numeric Rating Scale is a unidimensional measure of pain intensity from 0 (no pain) to 10 (high pain intensity) using a horizontal bar or line. ${ }^{20}$

The Brief Pain Inventory (BPI) is used to measure pain intensity and interference of pain in the everyday activities of the patient. ${ }^{21}$

The Oswestry Disability Index is a self-completed questionnaire comprising 10 topics (pain intensity; lifting; ability to care for oneself; ability to walk; ability to sit; sexual function; ability to stand; social life; sleep quality; ability to travel). Each question is scored on a scale of 0 (indicating the least amount of disability) and 5 (indicating most severe disability). The scores for all questions answered are summed and then multiplied by two to obtain the index: $0-20 \%$ denotes minimal disability; $21-40 \%$ represents moderate disability; $41-60 \%$ indicates severe disability; $61-80 \%$ denotes crippling back pain; $81-100 \%$ indicates the patient is bed-bound or has exaggeration of symptoms. ${ }^{22}$

\section{Imaging}

After physical examination, MRI of the lumbar spine demonstrated FJS (L5-S1) but also revealed an arthrogenous cyst of the left facet of L5-S1 compressing the root of S1 (Figure 1). Her medical records and imaging records were reviewed, and MRI data compared with radiographs.

Ozone (OT) for medical use was obtained from an ozone generator. The latter was composed of a high-voltage tube through which molecular oxygen was passed, and divided into molecules to generate ozone. ${ }^{23}$ OT comprised one session per week for 3 weeks. Each injection was $20 \mathrm{~cm}^{3}$ of ozone $(20 \mu \mathrm{g} / \mathrm{mL})$. Injections were 


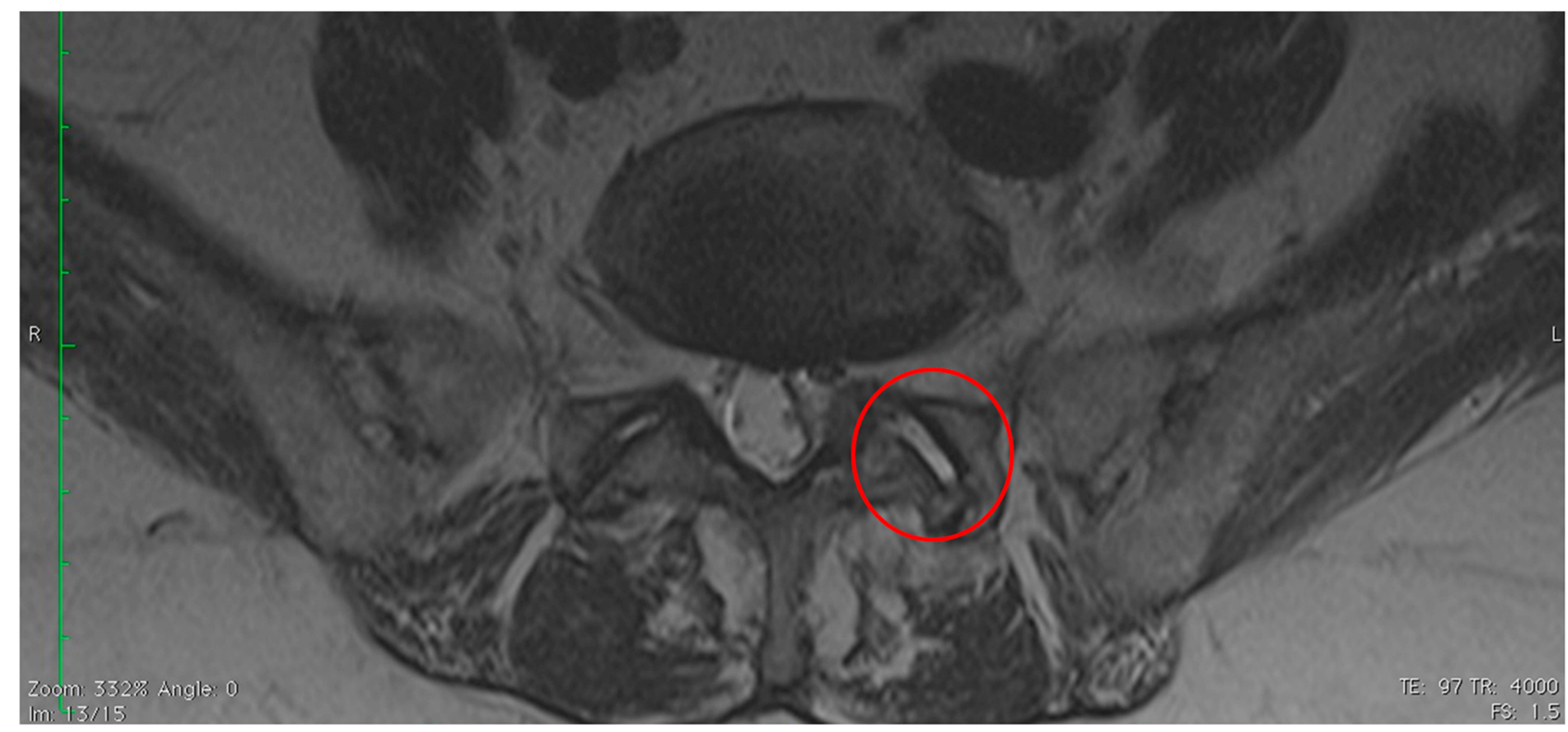

Figure I MR at baseline (T0). Image of the lumbar spine in T2 sequences; red circle highlights the L5-SI facet joint with evidence of osteoarthritis with effusion.

delivered under ultrasound guidance by two very experienced ultrasonographers. A linear probe $(6.0-13.0 \mathrm{MHz})$ and convex probe $(3-5.5 \mathrm{MHz})$ were employed to locate the left zygapophyseal joint between L5 and S1 accurately.

Injections were done with a $23-\mathrm{G}$ spinal needle for entering the facet joint. A $18-\mathrm{G}$ needle was used to aspirate ozone. A 24-G hypodermic needle was used for skin infiltration with ozone under ultrasound guidance.

The lumbar space to be punctured was submitted to an antiseptic procedure with gauzes soaked profusely in $70^{\circ}$ proof alcohol. Circular centrifugal movements from the center of the region to be punctured to the periphery were made, 3-5-times consecutively.

The patient lay prone on a bed. Once the entry site had been selected, the skin was marked at this position and local anesthetic infiltrated into the skin and superficial muscles. Then, the spinal needle was inserted vertically through this point until it reached the bone. Once it entered the joint, a "giving way" sensation was perceived. Some minor manipulation was needed to reach the joint space. The intraarticular location of the needle tip was confirmed by rotating the patient and observing the needle tip moving together with the facet joint. Post-procedurally, the patient was monitored for $20 \mathrm{~min}$ and then discharged home.

At 1 month after treatment, the patient was directed to a rehabilitation program. This involved aquatic rehabilitation for strengthening lumbar muscles and stabilizing pelvic muscles. Each session lasted $60 \mathrm{~min}$ and was done twice a week for 4 weeks in total. ${ }^{24}$

Overall, one adverse event was reported: ecchymosis at the injection site after the second session of OT that resolved spontaneously in 10 days. At T4, MRI of the lumbar region was done (Figure 2).

\section{Results}

After the first two sessions of OT, the patient stopped taking medications because of improvement in pain symptoms. Data from T0 to T2 show that she experienced

Table I Pain Scales During the Evaluation Times

\begin{tabular}{|l|l|l|l|l|l|l|l|}
\hline Evaluation Times & NRS at Rest & NRS at Movement & BPI - Pain & BPI - Mood & BPI - Sleep & BPI - Work & ODI \\
\hline T0 At baseline & 7 & 8 & 7 & 6 & 5 & 9 \\
T1 after two weeks & 3 & 5 & 3 & 4 & 3 & 54 \\
T2 after one month & 2 & 1 & 1 & 0 & 0 & 0 \\
T3 after two months & 0 & 0 & 0 & 0 & 0 & 0 \\
T4 after six months & 0 & 0 & 0 & 0 & 0 & 0 \\
\hline
\end{tabular}

Abbreviations: NRS (0-10), Numeric Rating Scale; BPI, Brief Pain Inventory; ODI (0-100\%), Oswestry Disability Index. 


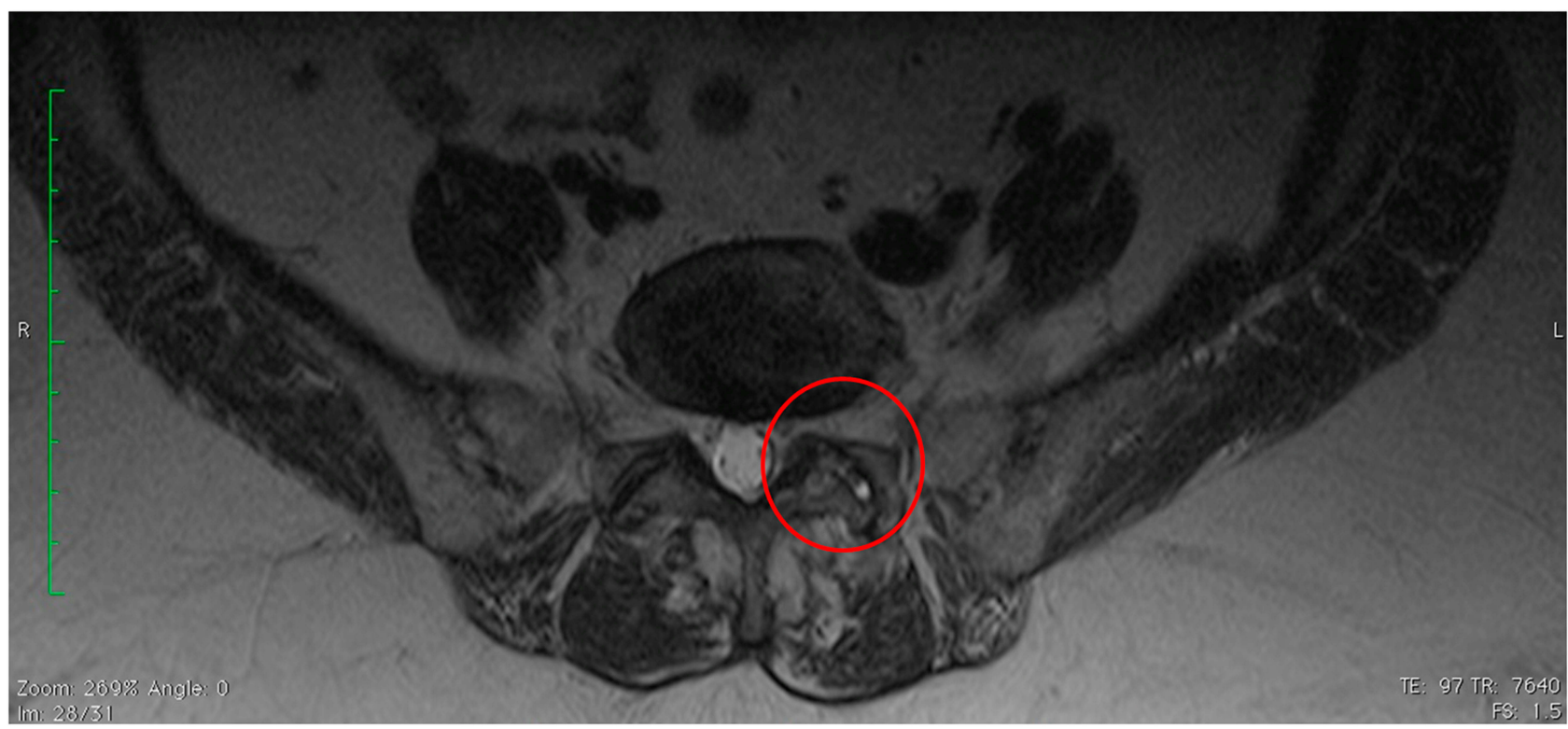

Figure 2 MR after 6 months (T4). Image of the lumbar spine in T2 sequences; red circle highlights the L5-SI facet joint with evidence of osteoarthritis without effusion.

a reduction in pain and a good result was maintained at follow-up (Table 1).

\section{Discussion}

We found that OT in FJS elicited encouraging results. After the first two sessions of OT, our patient stopped taking medications for LBP. Furthermore, the pain resolved at the end of rehabilitation and improvement was maintained at follow-up (T4). She did not experience side effects related to OT, which was conducted according to aseptic procedures.

The efficacy of OT against musculoskeletal disease has been shown in several studies. ${ }^{17-19}$ OT could be efficacious against spinal-degeneration diseases as well as acute and chronic inflammation. ${ }^{6}$ In LBP due to lumbar-disk herniation or FJS, OT could be an efficacious and valid alternative to conservative treatments that have failed. ${ }^{25-27}$ In FJS, the synovial villi within facet joints can become inflamed or trapped between articular processes, thereby producing pain, and OT can help to reduce such pain.

Ozone appears to interact with cytokines to generate an anti-inflammatory response that may contribute to pain. The painkilling effect of OT on osteoarthritis has been postulated to elicit some histologic changes. Some authors have reported a direct effect on the proteoglycans that make up the pulpous nucleus of vertebral disks. ${ }^{28}$ Exposure of the latter to ozone may result in cellular degeneration of the matrix which, in turn, is replaced by fibrous tissue with a consequent reduction in disk volume. Furthermore, ozone could have analgesic and anti-inflammatory effects by the reaction of reactive oxygen species with polyunsaturated fatty acids, lipid oxidation products, and anti-oxidants, which should counteract the pain induced by local C-nociceptors. ${ }^{29}$

Based on clinical practice and according to the principle of "hormesis" (ie, the beneficial effect of low-level exposure to an agent that is harmful at high levels), ${ }^{30}$ ozone at a low dose is a strong oxidant gas with antiseptic, immunomodulatory, analgesic, and anti-inflammatory properties. ${ }^{31} \mathrm{~A}$ mechanism of action has been proposed to explain the efficacy of ozone. First, ozone reduces the number of inflammatory components: ozone interrupts the inflammatory cascade by altering the breakdown of arachidonic acid so that production of proinflammatory prostaglandins is disrupted. ${ }^{26}$ Then, distension and inflammation of the synovial capsule cause blood stasis, which leads to tissue hypoxemia. However, by applying ozone, the oxygen concentration increases and causes hyperoxygenation of the area of interest. ${ }^{26}$ In addition, ozone allows stimulation of the repair process, promoting fibroblastic activity and inducing collagen deposition. ${ }^{25}$

Importantly, rehabilitation with aquatic exercises also contributed to the maintenance of the outcomes obtained with OT. Aquatic exercises are efficacious in conservative treatment of LBP. ${ }^{24}$ Aquatic exercises are often used in LBP management because they have important benefits compared with ground-based exercise and can help with balance, mobility, and pain control..$^{32}$ Exercises in warm water can facilitate muscle relaxation, and water buoyancy reduces joint loads. ${ }^{32}$ 


\section{Conclusion}

OT followed by aquatic exercises could be efficacious against the LBP caused by FJS.

\section{Disclosure}

The authors declare no conflicts of interest.

\section{References}

1. Beresford ZM, Kendall RW, Willick SE. Lumbar facet syndromes. Curr Sports Med Rep. 2010;9(1):50-56. doi:10.1249/JSR.0b0 $13 \mathrm{e} 3181 \mathrm{caba05}$

2. Wenger HC, Cifu AS. Treatment of low back pain. JAMA. 2017;318 (8):743-744. doi:10.1001/jama.2017.9386

3. Petersen T, Laslett M, Juhl C. Clinical classification in low back pain: best-evidence diagnostic rules based on systematic reviews. BMC Musculoskelet Disord. 2017;18(1):188. doi:10.1186/s12891-017-1549-6

4. Brinjikji W, Luetmer PH, Comstock B, et al. Systematic literature review of imaging features of spinal degeneration in asymptomatic populations. AJNR Am J Neuroradiol. 2015;36(4):811-816. doi:10. 3174/ajnr.A4173

5. Downie A, Hancockx A, Jenkins H, et al. How common is imaging for low back pain in primary and emergency care? Systematic review and meta-analysis of over 4 million imaging requests across 21 years. Br J Sports Med. 2019; pii: bjsports-2018-100087. doi:10.1136/ bjsports-2018-100087.

6. Seyam O, Smith NL, Reid I, et al. Clinical utility of ozone therapy for musculoskeletal disorders. Med Gas Res. 2018;8(3):103-110. doi:10.4103/2045-9912.241075

7. Greher M, Scharbert G, Kamolz LP, et al. Ultrasound-guided lumbar facet nerve block: a sonoanatomic study of a new methodologic approach. Anesthesiology. 2004;100(5):1242-1248. doi:10.1097/ 00000542-200405000-00028

8. Schwarzer AC, Aprill CN, Derby R, et al. Clinical features of patients with pain stemming from the lumbar zygapophysial joints. Is the lumbar facet syndrome a clinical entity? Spine. 1994;19 (10):1132-1137. doi:10.1097/00007632-199405001-00006

9. Marks RC, Houston T, Thulbourne T. Facet joint injection and facet nerve block: a randomised comparison in 86 patients with chronic low back pain. Pain. 1992;49(3):325-328. doi:10.1016/0304-3959(92)90239-8

10. Bogduk N, Ed. Practice Guidelines for Spinal Diagnostic and Treatment Procedures. International Spine Intervention Society; 2013.

11. Saal JS. General principles of diagnostic testing as related to painful lumbar spine disorders: a critical appraisal of current diagnostic techniques. Spine (Phila Pa 1976). 2002;27(22):2538-45; discussion 2546. doi:10.1097/00007632-200211150-00027

12. Glover JR. Arthrography of the joints of the lumbar vertebral arches. Orthop Clin North Am. 1977;8(1):37-42.

13. Cavanaugh JM, Ozaktay AC, Yamashita HT, et al. Lumbar facet pain: biomechanics, neuroanatomy and neurophysiology. $J$ Biomech. 1996;29(9):1117-1129. doi:10.1016/0021-9290(96)00023-1

14. Delitto A, George SZ, Van Dillen LR, et al. Orthopaedic section of the American Physical Therapy Association: low back pain. J Orthop Sports Phys Ther. 2012;42(4):A1-A57. doi:10.2519/jospt.2012.42.4.A1

15. Shipton EA. Physical therapy approaches in the treatment of low back pain. Pain Ther. 2018;7(2):127-137. doi:10.1007/s40122-018-0105-x.

16. Iliakis E, Valadakis V, Vynios DH, et al. Rationalization of the activity of medical ozone on intervertebral disc a histological and biochemical study. Rivista Di Neuroradiologia. 2001;14 (1_suppl):23-30. doi:10.1177/19714009010140S105
17. Andreula CF, Simonetti L, De Santis F, et al. Minimally invasive oxygen-ozone therapy for lumbar disk herniation. AJNR Am J Neuroradiol. 2003;24(5):996-1000.

18. Alexandre A, Corò L, Azuelos A, et al. Intradiscal injection of oxygen-ozone gas mixture for the treatment of cervical disc herniations. Acta Neurochir Suppl. 2005;92:79-82.

19. Alexandre A, Buric J, Paradiso R, et al. Intradiscal injection of $\mathrm{O} 2-\mathrm{O} 3$ to treat lumbar disc herniations. Riv Ital OssigenoOzonoterapia. 2002;1:165-169.

20. Hawker GA, Mian S, Kendzerska T, et al. Measures of adult pain: Visual Analog Scale for Pain (VAS Pain), Numeric Rating Scale for Pain (NRS Pain), McGill Pain Questionnaire (MPQ), Short-Form McGill Pain Questionnaire (SF-MPQ), Chronic Pain Grade Scale (CPGS), Short Form-36 Bodily Pain Scale (SF-36 BPS), and Measure of Intermittent and Constant Osteoarthritis Pain (ICOAP). Arthritis Care Res (Hoboken). 2011;63(Suppl 11):S240-S252. doi:10.1002/acr.20543

21. Cleeland CS, Ryan KM. Pain assessment: global use of the brief pain inventory. Ann Acad Med Singapore. 1994;23(2):129-138.

22. Fairbank JC, Pynsent PB. The oswestry disability index. Spine (Phila $P a$ 1976). 2000;25(22):2940-52; discussion 2952. doi:10.1097/ 00007632-200011150-00017

23. Lopes de Jesus CC, Dos Santos FC, de Jesus LMOB, et al. Comparison between intra-articular ozone and placebo in the treatment of knee osteoarthritis: a randomized, double-blinded, placebo-controlled study. PLoS One. 2017;12(7):e0179185. doi:10.1371/journal.pone.0179185

24. Shi Z, Zhou H, Lu L, et al. Aquatic exercises in the treatment of low back pain: a systematic review of the literature and meta-Analysis of eight studies. Am J Phys Med Rehabil. 2018;97(2):116-122. doi:10.1097/PHM.0000000000000801

25. Rahimi-Movaghar V, Eslami V. The major efficient mechanisms of ozone therapy are obtained in intradiscal procedures. Pain Physician. 2012;15(6):E1007-8.

26. Magalhaes FN, Dotta L, Sasse A, et al. Ozone therapy as a treatment for low back pain secondary to herniated disc: a systematic review and meta-analysis of randomized controlled trials. Pain Physician. 2012;15(2):E115-29.

27. Lu W, Li YH, He XF. Treatment of large lumbar disc herniation with percutaneous ozone injection via the posterior-lateral route and inner margin of the facet joint. World J Radiol. 2010;2(3):109-112. doi:10.4329/wjr.v2.i3.109

28. Paoloni M, Di Sante L, Cacchio A, et al. Intramuscular oxygen-ozone therapy in the treatment of acute back pain with lumbar disc herniation: a multicenter, randomized, double-blind, clinical trial of active and simulated lumbar paravertebral injection. Spine. 2009;34 (13):1337-1344. doi:10.1097/BRS.0b013e3181a3c18d

29. Leonardi M. Disc puncture under fluoroscopic guidance. Riv Ital Ossigeno-Ozonoterapia. 2002;1(1):73-78.

30. Goldman M. Cancer risk of low-level exposure. Science. 1996;271 (5257):1821-1822. doi:10.1126/science.271.5257.1821

31. Lehnert T, Naguib N, Wutzler S, et al. Analysis of disk volume before and after CT-guided intradiscal and periganglionic ozoneoxygen injection for the treatment of lumbar disk herniation. $J$ Vasc Interv Radiol. 2012;23:1430-1436. doi:10.1016/j.jvir.2012.07.029

32. Baena-Beato PA, Ártero EG, Arroyo-Morales M, et al. Aquatic therapy improves pain, disability, quality of life, body composition and fitness in sedentary adults with chronic low back pain. A controlled clinical trial. Clin Rehabil. 2014;28:350-360. doi:10.1177/0269215513504943 


\section{Publish your work in this journal}

The International Medical Case Reports Journal is an international, peer-reviewed open-access journal publishing original case reports from all medical specialties. Previously unpublished medical posters are also accepted relating to any area of clinical or preclinical science. Submissions should not normally exceed 2,000 words or 4 published pages including figures, diagrams and references. The manuscript management system is completely online and includes a very quick and fair peer-review system, which is all easy to use. Visit http://www.dovepress.com/testimonials.php to read real quotes from published authors.

Submit your manuscript here: https://www.dovepress.com/international-medical-case-reports-journal-journal 